

\title{
Sedimentary Ripple marks from pavements of forts in Jaipur, Rajasthan. India
}

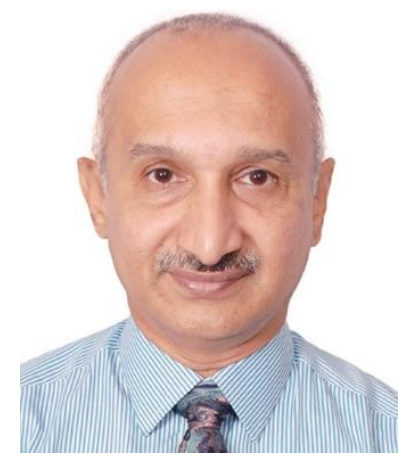

\section{Author \& Affiliation}

Guruswamy Srikanth, Akshaya Apartment. R10/4. $6^{\text {Th }}$ Avenue. Anna Nagar. Chennai 600040. India. Srikanth.4thparadigm@gmail.com

Quasquicentinnial $\left(125^{\text {th }}\right)$ Year Celebration Volume, Presidency College, Chennai 600005. India. Pages: 101-107. 2019.

\begin{abstract}
Prolific occurrence of a variety of ripple trains in popular forts of Jaipur are observed. The occurrence of extensive Geological sample within man-made buildings form a valuable record for a variety of teaching and research needs. Random samples from these rippled sandstone slabs are classified to highlight their variability. Few standard measures are made on a sample pointing to quantitative approaches possible with their digital images. The objective is to elucidate the variety and extent of the observed samples and to bring forward their measurement and interpretation possibilities. These easily accessible and interpretable structures are significant in teaching and research of sedimentology and stratigraphy. The occurrence and use of such vast treasures of Geological samples among the historical and modern human edifice is highlighted.
\end{abstract}

\section{Introduction}

Human activity had altered and removed innumerable sites containing important Geological features. However, a large number of hitherto inaccessible exposures and samples are available in places of social, commercial and industrial activities. Deep excavations for foundations, quarries, cliffs formed due to rock blasting and tunnels expose fresh and well-preserved Geological systems. Buildings are yet another location for excellent collection of samples for study. Entire flooring in large complexes are done with - well developed stylolite bearing limestones, microstructures of granites, complex flow patterns from gneisses. Examples are extensive in all areas, practically every large building using natural rock for floor or structure is a Geological museum.

Ripple marks are sedimentary structures produced by the interaction of waves or currents with the material on the sediment surface. They are formed in modern sedimentary environments by the small-scale processes that reshape the sediment into undulatory surface by systematic binning and motion of the loose particles. Found commonly in a great variety of scales and processes, ripple marks are seen from the active sedimentary systems to the most ancient rocks in Geology. They are subject of qualitative, quantitative and process sedimentological research for nearly 200 years.

Extensive, well-preserved and highly variable ripple marks in few thousands form the walk-ways and flooring slabs of two famous forts - Nahargarh and Jaigarh, in Jaipur. These walk-ways are a museum 
of ancient ripple marks and valuable for teaching and research in quantitative sedimentology. This paper presents a representative set of these samples and highlights the convenience and opportunity. The Geology of these forts, and the sedimentary successions are examined from literature to position these ripple marks in stratigraphy. Basic classification and few measurements are done on the digital image data of these ripples to showcase their variety and range. Importance and value of this extensive sample in teaching and research of Geology are pointed out to encourage more formal study and characterization of this magnificent sedimentary exhibition.

\section{Objective \& Scope}

1. Report the occurrence of a wide variety of ripple marks in sedimentary rocks used for building walkways within the famous ports of Jaipur

2. Demonstrate the variety of samples using simple metrics and measurements.

3. Provide an overview for studies in Sedimentology, Stratigraphy and Paleo-Environment analysis.

\section{Location}

Location - 1: Nahargarh fort - walk-way from the Jaipur Wax museum to Padao restaurant $(\Delta 560 \mathrm{~m}$, $\left.26^{\circ} 56^{\prime} 14.8^{\prime \prime} \mathrm{N} 75^{\circ} 48^{\prime} 43.6^{\prime \prime} \mathrm{E}\right)$.

Location - 2: Jaigarh fort - the walk-way to Jaivana Cannon ( $\left.\Delta 596 \mathrm{~m}, 26^{\circ} 58^{\prime} 28.80^{\prime \prime} \mathrm{N} 75^{\circ} 50^{\prime} 22.36^{\prime \prime} \mathrm{E}\right)$. \{elevations are taken from http://www.mapcoordinates.net/en for the locations\}

\section{Ripple Marked Sandstones}

A large number of sandstone slabs with extensive ripple marks are seen in the entire length and width of walk-ways in these two forts. In extent, variety and clarity they are among the best collection of sedimentary ripple marks in one location (Figure 1 ).

The formations within these 2 forts, are formed in a Proterozoic basin named as Alwar-Jaipur basin. The hills are made of Pratapgargh Formation of Alwar group from Delhi Super Group (DSG), consisting of well exposed quartzite, quartz-mica schist, dolomite and amphibolite. The sedimentary sequences were deposited in fluvial and marginal marine environments. However, these rocks have been subjected to low-medium grade metamorphism. Gupta (1964) recognised the finely bedded quartzite with individual beds forming less than $10 \mathrm{~cm}$ exhibiting current bedding and ripple marks. The construction of walkways used these $\sim 10 \mathrm{~cm}$ quartzite beds as pavement slabs with their topsurfaces featuring the extensive variety of ripple marks.

Photographs of some of these structures are taken with a simple personal camera under existing natural light (Figure 2 ). For digital image processing, the photographs require to be near orthogonal angle. Very good quality images can be obtained with modern cameras, suitable for a range of interpretations, analysis and studies. In this report, the images are then classified to identify their ripple pattern, one of the samples is processed for extraction of edges (Figure 4 ) and manual mapping of the ripple parameters are done as an example.

\section{Ripple Marks in Teaching and Research}

Ripple marks are among the earliest Sedimentological structures described in scientific journals. In 1788 , James Hutton used the presence of ripple marks along bedding planes of vertical beds in 'Siccar Point' and interpreted their formation as horizontal surfaces ${ }^{[1]}$. Early scientific record of description of ripples can be traced to Upper Ordovician (Richmond Group) from Ohio (Locke, 1838, p246). Description, classification, interpretation and process-response models of ripple marks are since studied by numerous workers. They hold active scientific interest with most recent work 
coming from Davis et.al (2017), who advocated the role of microbial mats (life forms) and biofilms in sculpting the sub-ripple-scale sedimentary textures.

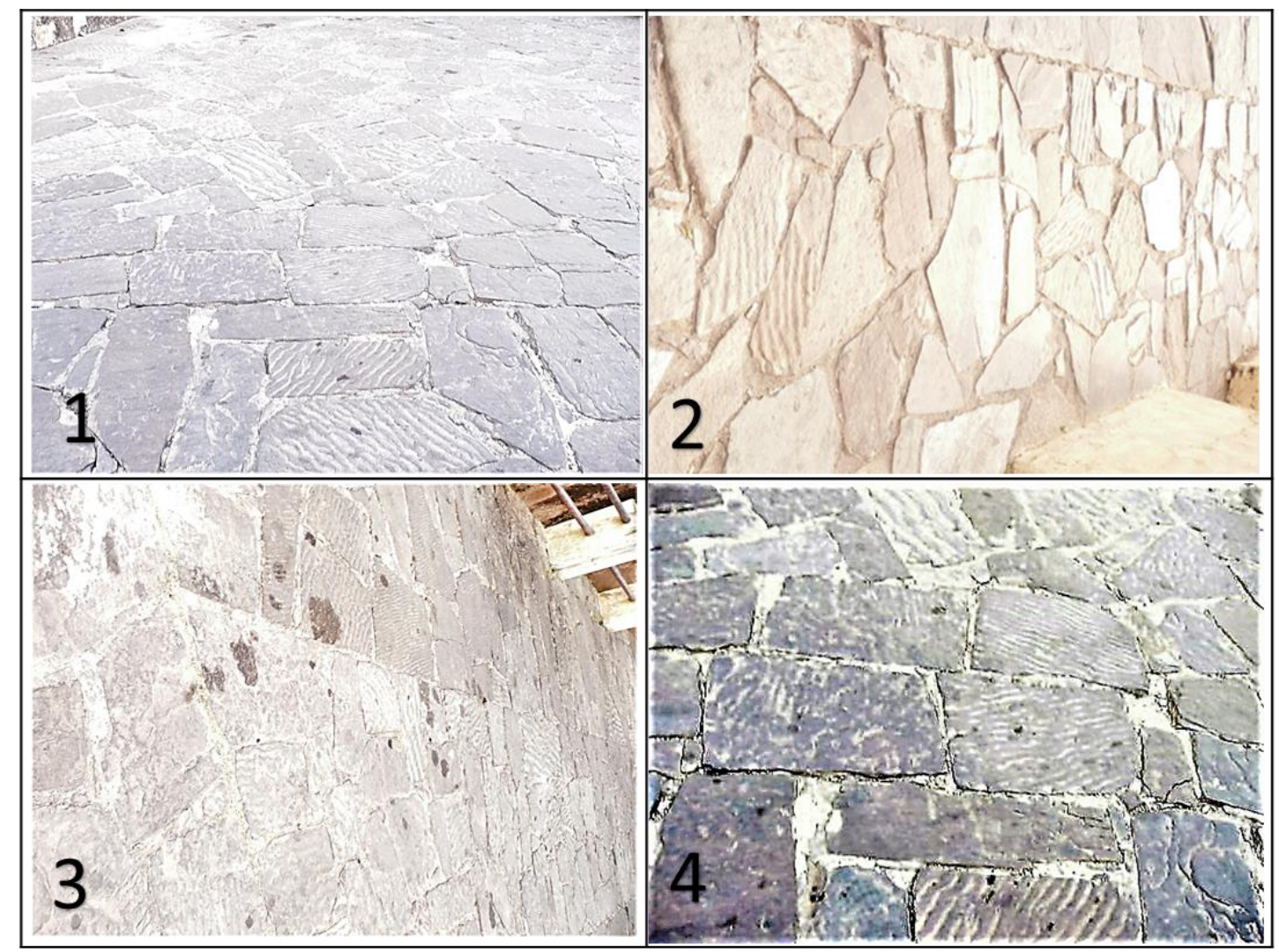

Figure 1 Ripple Ripples everywhere! View of the walk-ways in the Nahargarh and Jaigargh forts. Practically every slab is a unique ripple structure. These two locations have few hundreds of diverse and well preserved ripples among the walk-way slabs. It is possible that the ripple mark surface - a bedding plane favouring breaking into neat slabs led to such a large collection.

The samples from Jaipur fort can be used effectively in teaching and research. Few clear avenues are presented.

1. Description and Classification (Figure 2, Figure 3)

2. Metrics, Parameters and Modelling (Figure 4)

3. Process Sedimentology: Forward and Inverse Models

1. Description

A ripple is conventionally described using various terms of vertical and lateral profile representing its size and shape. Ripples are further described depending upon the nature of the crest in to $-\mathrm{i}$ ) Straight, ii) Undulatory, iii) Linguoid, iv) Cuspate, v) Lunate or iv) Rhomboid. Ripple trains (group of ripples as seen in the samples of this study) may form in-phase or out-of-phase undulations. Ripple marks occur in 4 orders of sizes from millimetre scale to 10 s of meters. The samples reported from Jaipur fort are 2 orders of sizes and scales.

The randomly picked samples of Ripple Structures show 4 main classes of ripples. Each of them have a refined diagnostic overprint of their depositional environment and represents distinctive energy and particle-size parameters of formation.

1. Unidirectional Current Ripples: Figure $2 \mathrm{~A}, \mathrm{~B}$ and $\mathrm{C}$ are representative of this group

Quasquicentinnial $\left(125^{\text {th }}\right)$ Year Celebration Volume, Presidency College, Chennai 600005. India. 


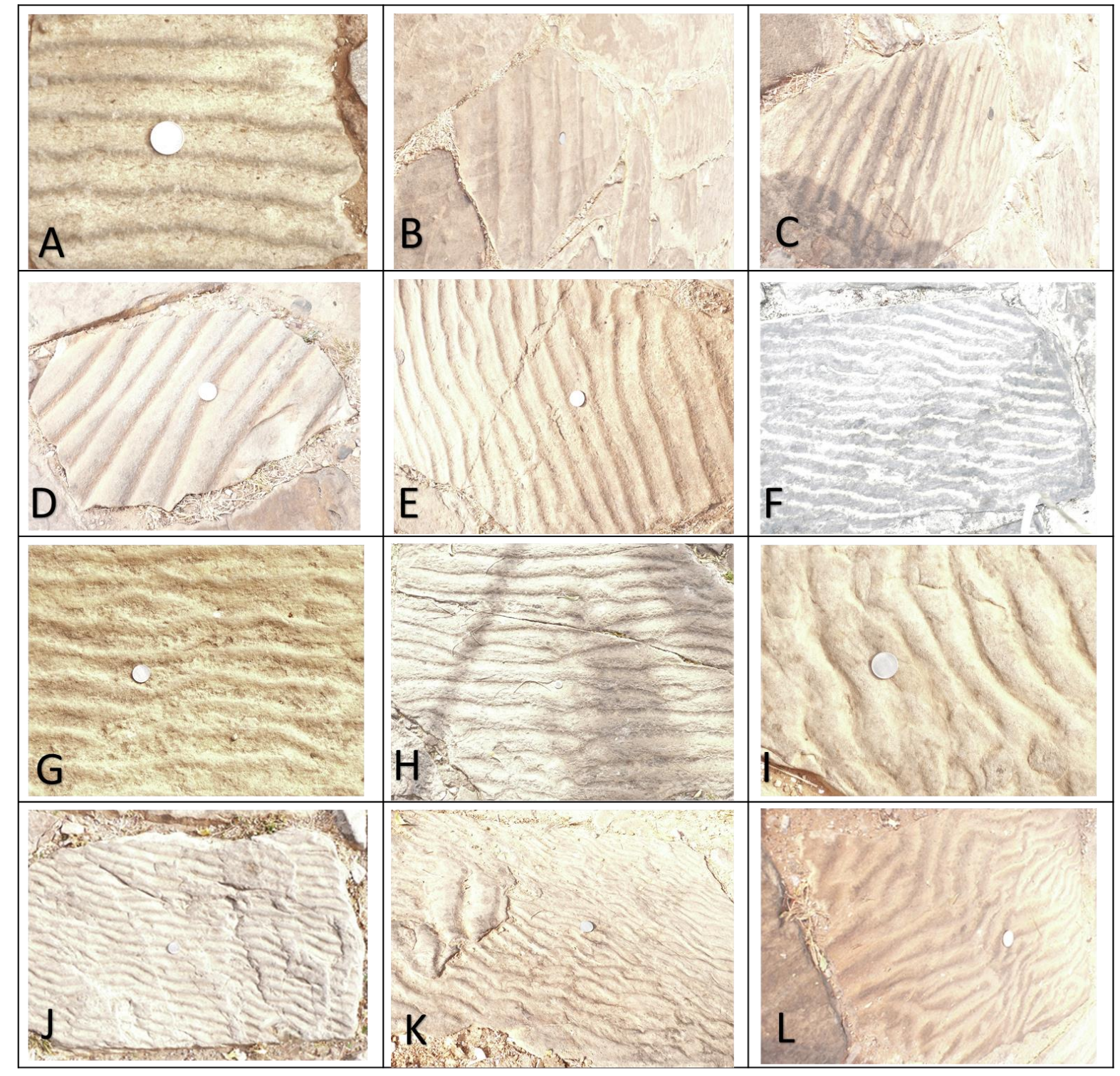

Figure 2 Representative ripple marks from the walk-ways of Jaipur forts. They are placed in order of increasing energy from - Small Straight current ripples $(A-C)$, Sinuous $(D, E, F)$, connected Linguoid $(G, H)$ to wave ripples (I, $J)$. The Superimposed ripples with out-of-phase crests are seen (K\&L). Samples $D$ and $F$ are from Jaigarh fort, while the others are from Nahargarh fort.

2. Undulatory Small Ripples: Figure $2 \mathrm{E}$ and $\mathrm{F}$ are classic undulations in ripple train. Figure 2 D shows the transition from Unidirectional ripple to undulation by symmetrically developed curvature on either side.

3. Wave Ripples: Symmetric and Asymmetric organization can be seen (Figure $2 \mathrm{G}$ and prominently in $2 \mathrm{I}$ ). Linguoid ripples can be seen in parts of the Figure $2 \mathrm{H}$ and $2 \mathrm{~K}$.

4. Sinuous Superimposed Ripples: Figure $2 \mathrm{I}$, is very similar to Sinuous ripple. Bifurcation, truncation and variable thickness of individual laminae can be seen in Figure $2 \mathrm{~K}$ and $2 \mathrm{~L}$.

Most of the classification of ripple marks are based on their mode of origin. The shape, size and origin are often combined in classification schemes (Figure 3). 


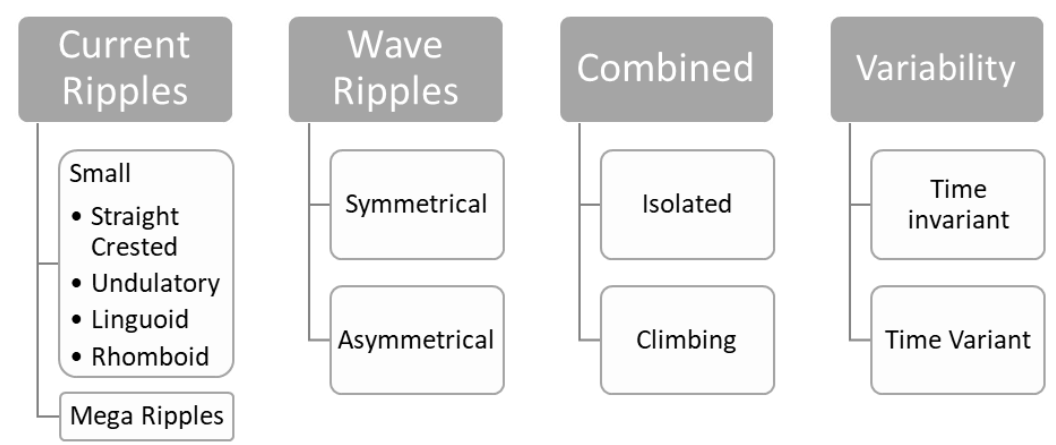

Figure 3 Classification of Ripples based on their mode of origin and temporal development

\section{Metrics and Parametric data}

There is large variety and number of well-preserved ripple structures in these forts. Systematic measurements on these samples opens quantitative methods of analysis. An example measure is made using the digital photograph and presented (Figure 4). This sample has Ripple Distances between 3-6cm ( $\sim \mathrm{cm}$ average); Bifurcation Index value of 0.38; Parallelism Index of 0.44 and Uniformity of form Index value of $\sim 0.5$. Tanner (1967), Reineck and Singh (1980, p35) and Diem (1985) provide the descriptions to various measures and their use in quantitative interpretation.

More formal methods using Digital Signal Processing (DSP), Feature detection, Edge extraction and other Image processing methods can also be taught and practiced.

The large number of samples available from Jaipur forts are good candidate to develop a database of ripple structures and measurements.

\section{Process Sedimentology. Forward and Inverse models}

A systematic measurement of the large number of samples and a database supports studies, teaching and research on quantitative Process Sedimentology.

Kaneko and Honji (1979), Arnott and Southard (1990) have used sample measurements on ripples, numerical simulation and experimental sedimentology to infer Process Sedimentology. Diem (1985) developed analytical expressions for evaluating paleo-depth and paleo-wave conditions from wave ripple mark measurements. The predictive power of these reconstructions in quantitative paleoenvironmental interpretation significant in addressing modern Geological and Ecological models.

The role of life-forms in building, preserving and altering the ripple marks is discussed by Altermann (2002). Kulkarni and Borkar (1996) reported trace fossils and meandering trails along the epirelief of the upper surface in rippled Bhander Sandstone (VSG). and Davies et.al (2017) studied sub-ripplescale sedimentary structures and identified the role of microbial mats and biofilms in sculpting and mediating the forms. Occurrence of such details can be investigated in the samples from Jaipur forts, for interpretations on early life of Proterozoic. 


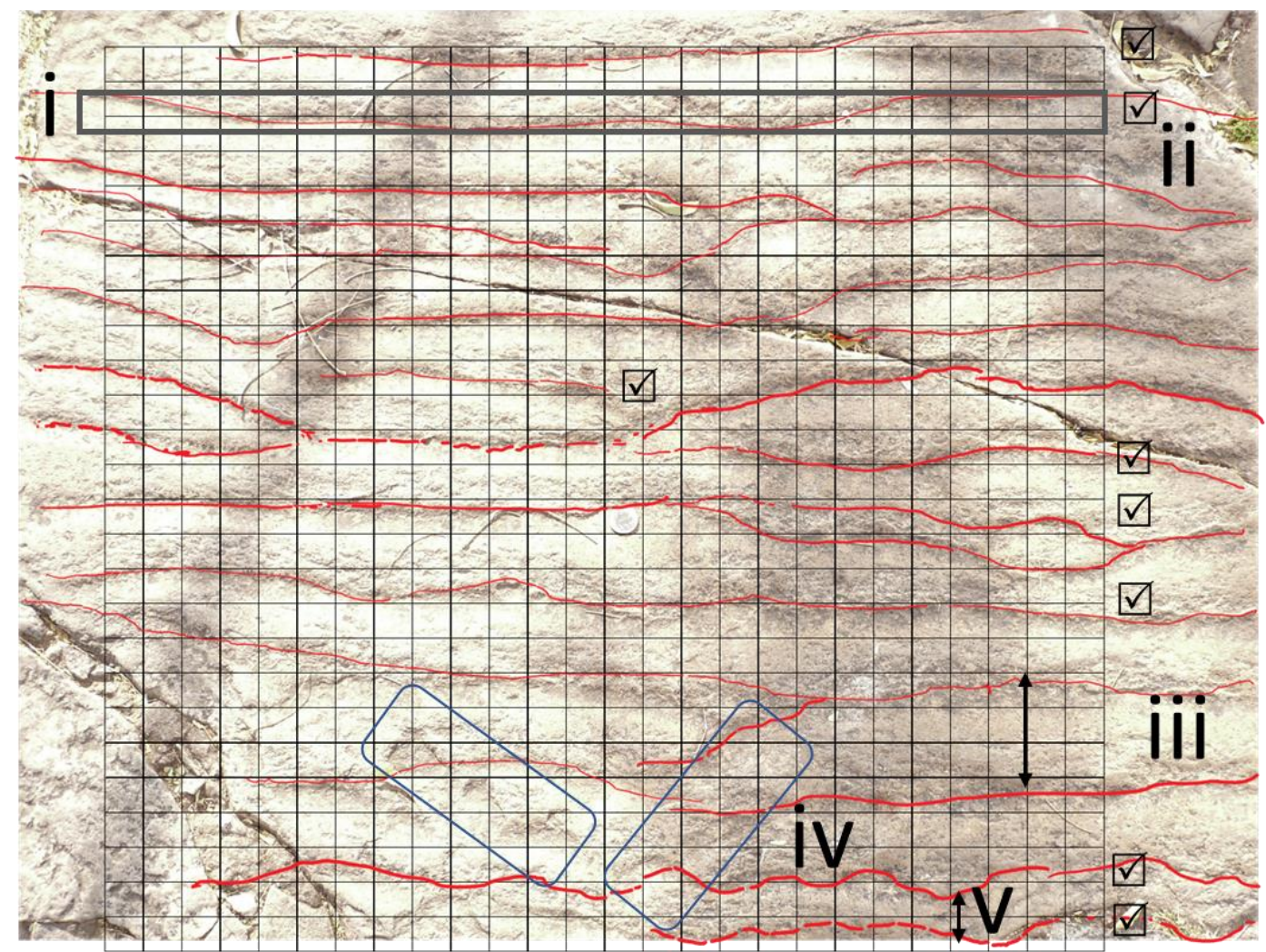

Figure 4 Template for measuring the different Ripple Parameters. (i) to (v) are pointers to the metrics taken from the image. The metrics are generated using an approximate $2 \times 2 \mathrm{~cm}$ grid and scaling it. Sample is $\sim 60 \times 52 \mathrm{~cm}$ size. i: Parallelism index bar; ii. Parallel ripple marks ;iii. Maximum ripple distance; iv: Linguoid ripples among Asymmetric bifurcated wave ripples; and v: Minimum ripple distance

\section{Sequence Stratigraphy}

Ripple marked surface represents a small period of non-deposition in the sedimentary sequence. Rapid transgressions and regressions are interpreted in many studies of ripple marks (Gupta, 1964). There is sufficient evidence of high frequency changes (intensity, direction and hiatus) during the formation and preservation of prolific ripple structures seen in numerous formations.

The excavation areas within and in the vicinity of Jaipur forts are most likely source of these sedimentary structures. They form a great sample for high resolution sequence stratigraphy.

\section{Discussion}

A Geological Sample is commonly collected from the place of its formation (in-situ) giving location, datum and stratigraphic level. Transported samples, like the ones reported in this note, do not have any locational information. Meteorites are samples collected at arbitrary locations and studied scientifically. Such samples are capable of providing reliable and useful information in many areas of investigation. They are valuable in developing - i) metrics/measurements, ii) morphometric classification; iii) methodology development; iv) parametric inter-relationships; and v) process response modelling.

Human edifices are source of Geological concepts since James Hutton who used the excavations in Forth and Clyde canal for various interpretations $(1767-1774)^{[1]}$. They continue to provide a very important and accessible geological section in all parts of the world. Polished rocks used in most modern buildings have large number of samples showcasing structure and mineralogy. Thousands of 
polished limestones bearing well-formed stylolite seams occur as flooring slabs in many buildings. Structural details are well highlighted in polished meta-Granites used in many temples of India.

These large number of high-grade samples, easily accessible and measurable form valuable sample for modern Geology teaching and research.

\section{Conclusions}

This study is prompted by the observance of numerous rippled sandstone slabs in the walk-ways of Jaipur forts. The note' aims are twofold: i) To report this distinctive repertoire of ripple-marks and ii) demonstrate the ease (and value) of doing effective scientific work using them.

The Geological community needs to be aware of these opportunities within their easy access and convert them into a valuable scientific resource. Teaching, Student projects and Advanced research can be conceived around such samples conveniently.

James Hutton, in 1753 letter ${ }^{[1]}$ wrote - "become very fond of studying the surface of the earth, and looking with anxious curiosity into every pit or ditch or bed of a river that fell in my way". This now includes - every building, pillar or floor.

\section{References}

Altermann, W. (2002) The Evolution of Life and its Impact on Sedimentation, Chapter-2 in Precambrian Sedimentary Environments: A Modern Approach to Ancient Depositional Systems (eds W. Altermann and P. L. Corcoran), Blackwell Publishing Ltd., Oxford, UK. doi: 10.1002/9781444304312.

Arnott, R.W., and Southard, J.B., 1990. Exploratory flow-duct experiments on combined-flow bed configurations, and some implications for interpreting storm-event stratification. Journal of Sedimentary Petrology, 60: 211-219.

Davies, N.S., A.P. Shillito and W.J. Mcmahon. (2017). Short-term evolution of primary sedimentary surface textures (Microbial, Abiotic, Iconological) on dry stream bed: Modern observations and ancient implications. Palaios, 32(3),125-134.

Diem, B. (1985). Analytical method for estimating palaeowave climate and water depth from wave ripple marks. Sedimentology, 32(5),705-720. (DOI:10.1111/j.1365-3091.1985.tb00483.x)

Gupta, B.D. (1964). Progress report for the field season 1963-64. Geology around - Jaipur, Rajasthan. Geological Survery of India. GSI-WRO-827. Pp.12. https://goo.gl/VLDu2u accessed on 18-04-2017

[1] Hutton, James, and John Playfair. "James Hutton." age (1797). https://www.revolvy.com/topic/James\%20Hutton\&item type=topic accessed on 12-07-2017

Kaneko, A. and H. Honji (1979). Initiation of ripple marks under oscillating water. Sedimentology 26(1)101-113.

Kulkarni, K.G., and Borkar, V.D. (1996). Occurrence of Cochlichnus Hitchcock in the Vindhyan Supergroup (Proterozoic) of Madhya Pradesh. Jour. Geol. Soc. India 47(6) 725-729.

Locke, J (1838). In Ohio. Chief Geologist. First[-second] Annual Report on the Geological Survey of the State of Ohio: [1837-1838]. Columbus: S. Medary, printer to the state. p:201- 286. https://catalog.hathitrust.org/Record/010688861 accessed on 12-07-2017 